Gut, 1966, 7, 569

\title{
Coeliac thoughts
}

Only 10 years ago the small intestinal mucosa was almost undiscovered as a source of pathological material. Since Shiner performed the first peroral biopsy in $1956^{1}$ tubes and capsules have been invented by the dozen and a wholesale attack on the jejunal mucosa has followed. As with all good techniques there have been rich rewards but the major achievement has been the recognition of an abnormal flattened mucosa that accompanies coeliac disease of childhood and idiopathic steatorrhoea or adult coeliac disease. With the increasing use of jejunal biopsy and a great renewal of interest in small intestinal function and its relation to anaemias, coeliac disease is being diagnosed with greater frequency. Furthermore a flat mucosa is found in some individuals who have only minor or trivial complaints. There is no correlation between the finding of a flat mucosal specimen in a single biopsy and the clinical state of the patient. Have they all got coeliac disease? It would seem better for the moment to say that any patient with a flat mucosa has a coeliac syndrome.

Not only is a flat mucosa commonly discovered at biopsy but it is being reported in association with other diseases. Furthermore the suggestion is advanced that these associations are significant and the mucosal abnormality has been produced by the other diseases ${ }^{2}$. In this hypothesis coeliac disease of childhood and adult coeliac disease or idiopathic steatorrhoea are primary coeliac syndromes while those instances where the mucosal change and the resulting malabsorption are produced by another disease are secondary coeliac syndromes. Response to gluten withdrawal has been reported ${ }^{6}$ in both primary and secondary coeliac syndromes ${ }^{3}$. Other authorities believe that there is only one entity and a flat mucosa is the diagnostic feature of it $^{4}$. This argument appears to be a circular one: adult coeliac disease may be defined as a malabsorption state with a flat jejunal mucosa and a response to gluten withdrawal, therefore any patient with a flat mucosa and an improvement on a gluten-free diet has adult coeliac disease. But this is rather like saying that any patient with a megaloblastic anaemia who responds to vitamin $\mathbf{B}_{12}$ has pernicious anaemia, which might have been acceptable some years ago. There seems to be no criterion currently available to define adult coeliac disease other than the jejunal biopsy; we are at the same stage as having only the morphology of a megaloblastic marrow without the knowledge of vitamin $B_{12}$ metabolism. (The known association of adult coeliac disease with blood group $\mathrm{O}$ might be a possible help in discriminating two syndromes ${ }^{5}$.) However, in spite of this semantic difficulty there are some convincing records of secondary coeliac syndromes and it seems worth pursuing the question; is a flat jejunal biopsy a specific histological finding indicating a single disease entity or is it a non-specific appearance compatible with several causative agents and various natural histories?

Before deciding how this question should be answered the available evidence must be marshalled. At the outset the question of response to gluten withdrawal must be considered. Some workers will only diagnose coeliac disease when a response to gluten withdrawal has been demonstrated (and a few even demand relapse on reintroducing gluten). In all adult series there is a sizable minority of patients, up to $25 \%$, who do not show this response in spite of a typically flat jejunal biopsy $3,6,7,8$. Coeliac disease of childhood is different in having an almost universal sensitivity to gluten and its withdrawal. Up to date no other toxic agent has been isolated, except perhaps for lactose in infants ${ }^{9}$, and it remains possible that further destructive mechanisms will emerge. However, the lack of an enzyme for dealing with gluten may well be non-specific just as a deficiency of lactase seems an occasional accompaniment of other intestinal diseases.

The bulk of evidence lies in the association of the coeliac syndrome with other disease. A coeliac syndrome has been described in association with malignancy, both carcinoma and lymphoma, within or without the gut ${ }^{10,11}$. A word of caution is needed here as there is no doubt that lymphoma and probably carcinoma of the small intestine may arise as a complication of a longstanding coeliac syndrome $^{12}$. Generalized disease such as diabetes ${ }^{213}$, sarcoidosis ${ }^{2}$, and Sjögren's syndrome ${ }^{14}$ are 
reported with a coeliac syndrome. Infective hepatitis has been found to have mucosal lesions and a flat mucosa has spontaneously recovered in convalescence ${ }^{15}$; a marked mucosal change has been reported in mice with a virus infection ${ }^{\mathbf{1 6}}$. Steatorrhoea and a flat mucosa have been found in ulcerative colitis and improvement in the coeliac syndrome has been reported in parallel with remission of the colitis ${ }^{\mathbf{1 7}}$. Other gastrointestinal lesions have been found with a coeliac syndrome: post-gastrectomy states ${ }^{2}$ and pancreatic disease ${ }^{2}$. Perhaps not surprisingly infestations of the gut have caused mucosal abnormalities and a coeliac syndrome secondary to giardia lamblia ${ }^{18,19}$, ankylostoma duodenale ${ }^{20,21}$, strongyloides ${ }^{22}$, and coccidiosis $^{23}$ is on record. Dermatitis is well known to accompany a primary coeliac syndrome but the reverse association of a coeliac syndrome secondary to skin disease is also reported: widespread dermatitis ${ }^{2}$ and acne rosacea are incriminated ${ }^{24}$. From Uganda has come a biopsy study of kwashiorkor with $10 \%$ of children having a flat jejunal mucosa ${ }^{25}$, while from America a remarkable report of two patients with obesity who after strict dieting and weight loss developed a brisk coeliac syndrome complete with flat mucosa ${ }^{26}$. Experimental support for a nutritional mechanism is to hand in work on pigs using a low-protein, high-calorie intake, where mucosal lesions very like the coeliac lesion were produced ${ }^{27}$. A flat mucosa has also been found in some cases of tropical sprue in Puerto Rico ${ }^{28}$. From Australia there is a description of a new entity of severe diarrhoea in young infants a few days to a few weeks old in whom some had a flat mucosa and both clinical and histological response was obtained solely by lactose withdrawal ${ }^{9}$. The same group of workers have also produced a flat mucosa in animals by non-specific chemical and physical irritation to transplanted mucosa ${ }^{29}$. Finally mention must be made of the difficult matter of the association between hypo- and agammaglobulinaemia and the coeliac syndrome. This has been reported both in sporadic and familial cases but a scrutiny of the literature gives no definite lead as to which is the primary event ${ }^{30,31,32,38}$.

Among all these reports are some where it seems certain that the coeliac syndrome is secondary and in those where the mucosa has recovered spontaneously with improvement of the associated disease or infection the lesion can hardly be said to be specific. For the majority of instances listed above, however, the question remains. Is this a true association or the chance finding of two diseases in one patient which is known to bedevil hospital figures ? $^{34}$ It must now be clear that this question can only be answered by epidemiology. If the prevalence of the coeliac syndrome in the whole population was known then the likelihood of the associations listed above being true ones or due to chance could be tackled.

Epidemiology has proved a useful tool in many aspects of gastrointestinal disease, the American ${ }^{35}$ and Oxford ${ }^{36}$ studies of ulcerative colitis being models of their kind. But at once a difficulty emerges; ulcerative colitis is a vivid clinical picture and diagnosed with some ease so that almost every case will come to a doctor and eventually to an epidemiologist. By contrast the coeliac syndrome is diffuse in its presentation and the patient may arrive at haematological, metabolic, neurological, dermatological, or psychiatric clinics. The range of absorptive tests is enormous and almost all show overlap with other diseases. Jejunal biopsy is the one criterion on which a definite diagnosis can be made, though radiology and a response to gluten withdrawal are very suggestive in some cases. To complicate the issue further it is clear that some cases may present with a very mild, chronic illness and an unknown number of people with minor or even no symptoms must be undetected in the normal population. Until a simple screening test for the coeliac syndrome is dicovered the only method of epidemiological study would be a biopsy investigation of a sample of the normal population, which is virtually impossible.

The small intestinal mucosa can be examined at necropsy by the dissecting microscope ${ }^{37}$. This gives a clear picture of mucosal structure and a flat and a convoluted mucosa can be recognized and distinguished from a more normal pattern of finger and leaf shape villi. A survey of cases of sudden death might give a helpful view of part of the 'normal' population. This method has already shown that abnormal mucosal changes in the upper small intestine occur in many cases dying of chronic illnesses, particularly malignancy ${ }^{38}$. Some of these are the same as those found in cases of the coeliac syndrome at necropsy though tending to be more localized to the proximal small intestine. 
At the present time the position can be best summarized as follows. A flat jejunal mucosa is not specific in every instance. Primary coeliac syndromes are commonly found and many are probably undetected. Some associations are found in clinical practice between other diseases and a coeliac syndrome and here the case is non-proven until more evidence of an epidemiological nature is available. In the meantime the more these associations are looked for and reported the clearer the picture will become.

BRIAN CREAMER

\section{REFERENCES}

${ }^{1}$ Shiner, M. (1956). Jejunal-biopsy tube. Lancet, 1, 85.

${ }^{2}$ Hindle, W. and Creamer, B. (1965). Significance of a flat small-intestinal mucosa. Brit. med. J., 2, 455-458.

3 _ . (1965) Clinical picture accompanying a flat small-intestinal mucosa Brit. med. J., 2, 458-459.

‘Rubin, C. E. (1961). Malabsorption: celiac sprue. Ann. Rev. Med., 12, 39-54.

${ }^{5}$ Joske, R. A. and Benson, J. A., Jr. (1958). A.B.O. blood groups and nontropical sprue. Gastroenterology, 34, 408-409.

${ }^{6}$ French, J. M., Hawkins, C. F., and Smith, N. (1957). The effect of a wheat-gluten-free diet in adult idiopathic steatorrhoea: a study of 22 cases. Quart. J. Med., 26, 481-499.

${ }^{7}$ Sleisenger, M. H. (1961). Clinical and metabolic studies in nontropical sprue. New. Engl. J. Med., 265, 49-56.

${ }^{8}$ Benson, G. D., Kowlessar, O. D., and Sleisenger, M. H. (1964). Adult coeliac disease, with emphasis upon response to the gluten-free diet. Medicine (Baltimore), 43, 1-40.

${ }^{9}$ Burke, V., Kerry, K. R., and Anderson, C. M. (1965). The relationship of dietary lactose to refractory diarrhoea in infancy. Aust. paediat. J., 1, $147-160$.

${ }^{10}$ Creamer, B. (1964). Malignancy and the small-intestinal mucosa. Brit. med. J., 2, 1435-1436.

"Wangel, A. G. and Deller, D. J. (1965). Malabsorption syndrome associated with carcinoma of the bronchus. Gut, 6, 73.

${ }^{12}$ Gough, K. R., Read, A. E., and Naish, J. M. (1962). Intestinal reticulosis as a complication of idiopathic steatorrhoea. Gut, 3, 232.

${ }^{13}$ Vinnik, I. E., Kern, F., Jr., and Struthers, J. E., Jr. (1962). Malabsorption and the diarrhea of diabetes mellitus. Gastroenterology, 43, 507-520.

${ }^{14}$ Pittman, F. E. and Holub, D. A. (1965). Sjögren's syndrome and adult celiac disease. Gastroenterology, 48, 869-876.

${ }^{15}$ Astaldi, G., Grandini, U., Poggi, C., and Strosselli, E. (1964). Intestinal biopsy in acute hepatitis. Amer. J. dig. Dis., 9, $237-245$.

${ }^{16}$ Biggers, D. C., Kraft, L. M., and Sprinz, K. (1964). Lethal intestinal virus infection of mice. Amer. J. Path., 45, 413-422.

${ }^{17}$ Salem, S. N., Truelove, S. C., and Richards, W. C. D. (1964). Small intestinal and gastric changes in ulcerative colitis: a biopsy study. Brit. med. J., 1, 394-398.

${ }^{18}$ Cameron, A. H., Astley, R., Hallowell, (M., Rawson, A. B., Miller, C. G., French, J. M., and Hubble, D. V. (1962). Duodenojejunal biopsy in the investigation of children with coeliac disease. Quart. J. Med., 31, 125-140.

${ }^{19}$ Yardley, J. H., Takano, J., and Hendrix, iT. R. (1964). Epithelial and other mucosal lesions of the jejunum in giardiasis: jejunal biopsy studies. Bull. Johns Hopk. Hosp., 115, 389-406.

${ }^{20}$ Sheehy, T. W., Meroney, W. H., Cox, R. S., Jr., and Soler, J. E. (1962). Hookworm disease and malabsorption. Gastroenterology, 42, $148-156$.

${ }^{21}$ Salem, S. N. and Truelove, S. C. (1964). Hookworm disease in immigrants. Brit. med. J., 1, 1074-1077.

${ }^{22}$ Milner, P. F., Irvine, R. A., Barton, C. J., Bras, G., and Richards, R. (1965). Intestinal malabsorption in Strongyloides stercoralis infestation. Gut, 6, 574-581.

${ }^{23}$ French, J. M., Whitby, J. L. and Whitfield, A. G. W. (1964). Steatorrhea in a man infected with coccidiosis (Isospora belli). Gastroenterology, 47, 642-648.

${ }^{24}$ Watson, W. C., Paton, E., and Murray, D. (1965). Small-bowel disease in rosacea. Lancet, 2, 47-50.

${ }^{25}$ Stanfield, J. P., Hutt, M. S. R., and Tunnicliffe, R. (1965). Intestinal biopsy in kwashiorkor. Lancet, 2, 519-523.

${ }^{26}$ Pittman, F. E. (1966). Primary malabsorption following extreme attempts to lose weight. Gut, 7, 154-158.

${ }^{27}$ Platt, B. S., Heard, C. R. C., and Stewart, R. J. C. (1964). The effects of protein-calorie deficiency on the gastrointestinal tract. In The Role of the Gastrointestinal Tract in Protein Metabolism. pp. 227-237. Blackwell, London.

${ }^{28}$ Swanson, V. L. and Thomassen, D. V. M. (1965). Pathology of the jejunal mucosa in tropical sprue. Amer. J. Path., 46, 511-551.

${ }^{29}$ Townley, R. R. W., Cass, M. H., and Anderson, C. M. (1964). Small intestinal mucosal patterns of coeliac disease and idiopathic steatorrhoea seen in other situations. Gut, 5, 51-55.

${ }^{30}$ Huizenga, K. A., Wollaeger, E. F., Green, P. A., and McKenzie, B. F (1961). Serum globulin deficiencies in non-tropical sprue, with report of two cases of acquired agammaglobulinemia. Amer. J Med., 31, 572-580.

${ }^{31}$ Pelkonen, R., Siurala, M., and Vuopio, P. (1963). Inherited agammaglobulinemia with malabsorption and marked alterations in the gastrointestinal mucosa. Acta med. scand., 173, 549-555.

${ }^{32}$ Allen, G. E. and Hadden, D. R. (1964). Congenital hypogammaglobulinaemia with steatorrhoea in two adult brothers. Brit. med. J., 2, 486-490.

${ }^{33}$ Crabbe, P. A. and Heremans, J. F. (1966). Lack of gamma A-immunoglobulin in serum of patients with steatorrhoea. Gut, 7, $119-127$.

${ }^{34}$ Berkson, J. (1946). Limitations of the application of the fourfold table analysis to hospital data. Biomet. Bull., 2, 47-53.

${ }^{35}$ Nefzger, M. D. and Acheson, E. D. (1963). Ulcerative colitis in the United States Army in 1944. Gut, 4, 183.

${ }^{36}$ Edwards, C. and Truelove, S. C. (1963). The course and prognosis of ulcerative colitis. Gut, 4, 300.

${ }^{37}$ Creamer, B. and Leppard, P. (1965). Post-mortem examination of a small intestine in the coeliac syndrome. Gut, 6, 466.

${ }^{38}$ Loehry, C. A. and Creamer, B. (1966). Post-mortem study of small intestinal mucosa. Brit. med. J., 1, 827-829. 